\title{
3 Research Square

\section{A Bibliometric Analysis and Visualization of Current Research Trends in the Treatment of Plantar Fasciitis}

\section{Xiaoyan Xu}

Long Hua Hospital

\section{Yijun Sun}

Shanghai Sixth Peoples Hospital

\section{Jiale Zheng}

Long Hua Hospital

Chongqing $\mathrm{Xu}$

Long Hua Hospital

\section{Qingshan $\mathrm{Ma}$}

Long Hua Hospital

\section{Xing Ding}

Long Hua Hospital

Mengchen Yin ( $\nabla$ yinmengchen0513@126.com )

Longhua Hospital https://orcid.org/0000-0001-7404-1495

\section{Junming Ma}

Long Hua Hospital

\section{Research article}

Keywords: bibliometric analysis, citespace software, plantar fasciitis, research trends, visualization, VOS viewer

Posted Date: March 2nd, 2021

DOl: https://doi.org/10.21203/rs.3.rs-255342/v1

License: (c) (i) This work is licensed under a Creative Commons Attribution 4.0 International License. Read Full License 


\section{Abstract}

Plantar fasciitis has become a common health problem. Both in theory and in therapy of plantar fasciitis has progressed rapidly in the past few decades, but there were no bibliometric studies regarding plantar fasciitis. This study aimed to illustrate the overall knowledge structure and development trends of plantar fasciitis. The research datasets were collected from the Web of Science, limited to articles published before Dec 16, 2020. VOS viewer and Citespace software were provided to analyze the data and generate visualization knowledge maps, including annual trends of publications, distribution, h-Index status, citations status, co-authorship status and research hotspots. 1429 publications met the requirement. The number of publications showed an upward trend with a stable rise in recent years. In the fields of plantar fasciitis, the United States published most papers $(493,34.50 \%)$, both total citations (13268) and h-index (65) ranked first of all the countries; the most productive institution was La Trobe University (30); Foot \& Ankle International (122) published the most papers. Growth factor, wave therapy, corticosteroid, foot function index and physical therapy were the research hotspots in the recent years. Indeed, this study provides great insights to the growth and development of plantar fasciitis. Moreover, it will contribute to the growth of the international frontier of plantar fasciitis. Level of Evidence II.

\section{Introduction}

Plantar fasciitis (PF), occurring in $11 \%$ to $15 \%$ of adults, has become a common public health concern. Mechanical overload, whether the result of biomechanical faults, obesity, or work habits of prolonged standing and running, contributes most to PF. ${ }^{1,2}$ The damage from overloading leads to aseptic inflammation of the fascia or tendon. 3,4 Patients usually feel painful on initiation of weight bearing, and the plantar heel pain usually occurring at the origin of the plantar fascia from the medial tubercle of the calcaneus. The pain tends to decrease after a few minutes`adaptation.

PF has progressed in the past few decades both in theory and in therapy, but many topics still remain controversial, such as the natural history of PF, scoring system to evaluate the severity of PF, objective judgment to choose between conservative and surgical treatment, predictors of treatment outcome, and so on. 5,6

Bibliometrics is a special type of quantitative and qualitative analysis in knowledge fields, using mathematics, statistics, philology, and other professional knowledge and methods to analyze the research achievement distribution of a current status comprehensively. So it has contributed a lot in governing policymaking and better understanding scientific fields. ${ }^{7-10}$

However, to our knowledge, bibliometric studies concerning the trend of the published literature of articles published in the field of PF has not yet been reported. This study aimed to intuitively show the research framework, overall knowledge structure, and development trends of the field of PF. We hope that this study will help scientific researchers better understand the research status and frontier trends. 
Furthermore, the results can also provide useful information and references for further investigation and publication.

\section{Materials And Methods}

\subsection{Search strategy and refined data}

The data for this study were collected from the Web of Science (WOS). WOS is the most widely accepted tool for the subsequent bibliometric analysis due to its strict evaluation process. The search term was *plantar fasciitis*. The literature search was limited to articles published before Dec 16, 2020. Original articles and reviews were included in this study, while letter, editorial material, basic research article and correction were excluded in our finalized dataset. Two independent researchers respectively reviewed and evaluated the cited articles to perfect the research. All different opinions were discussed until consensus was reached.

\subsection{Data analysis}

All data were extracted and imported into Microsoft Excel 2017. Annual trends of publications, distribution, citation and $\mathrm{H}$-Index status, co-authorship status, research hotspots and co-citation status were quantitatively and qualitatively. All statistical analyses were performed using SPSS 20.0. Statistical significance was considered at $P<0.05$. VOS viewer and Citespace are software tools for creating maps based on various layouts data and for visualizing and exploring the maps. In this study, these software were used for analyzing and visualizing co-citation of references, co-occurrence and timeline view of keywords. ${ }^{11-13}$

\section{Results}

\subsection{The Current Status and Annual Trend of Study}

A total of 1429 articles were identified in WOS database and analyzed with an additional manual screening according to the inclusion criteria, among which 180 are reviews and 1048 are original articles. Fig.1A shows the selection flow chart. The sum number of citation is 31204 (19336 without selfcitations). The average citation of all the papers is 21.84 times. The $\mathrm{H}$-index of all the publications is 85 .

Fig.1B shows the annual trends of publication numbers. Overall, there was an upward trend with a stable rise of the number of publications since 1995. There was a peak in the number of studies from 2018 to 2020 . A total of $107(7.49 \%)$ articles were published in 2018 , the highest in all years, followed by the year $2020(106,7.42 \%)$ and the year 2019(100, 7.00\%). The result indicated that more and more efforts and exploration had been made on PF.

\subsection{The Distribution and Co-authorship Analysis of Countries}


A total of 59 countries contributed to the field of PF research. But the majority of the papers were published in only a few countries. Fig.2A shows the top 10 most productive countries in PF field. There were 950 papers $(66.5 \%)$ published in the top 5 countries. The United States published the largest number of articles (493, 34.50\%), followed by China (129, 9.03\%), Germany $(117,8.19 \%)$, UK (109, 7.63\%), and Australia (102,7.14\%). H-index is a reliable and authentic parameter for academic evaluation. The $\mathrm{H}$-index of USA ranked first (65), followed by Germany (34), UK (31), and Australia(31). Furthermore, the number of citations can reflect the quality of a paper. Articles from USA were cited 13268 times, ranked first of all the countries, followed by Germany (3325) and Australia (3320). The result shows that USA is the country with the highest productivity, not only in qualities, but also in quantities. China, Germany, UK and Australia are the other most contributing countries. Fig.2C shows a map of worldwide research productivity, only countries published more than 10 articles were included. It shows that research on PF was concentrated in only a few countries during recent decades, more regions hadn 't participated in the field of PF yet. The Citespace viewer software was employed to analyze the network visualization of co-authorship relationship. (Fig.2B) USA was at the center of research, the cooperation between countries were relatively weak.

\subsection{The Distribution and Co-authorship Analysis of Institutions}

A total of 1691 institutions contributed to the field of PF research. The top 10 most productive institutions in the PF field are summarized in Fig.3A. La Trobe University published the largest number of articles (30), follow by Harvard University (18) and Hong Kong Polytech University (18). The H-index of La Trobe University and University Munich ranked first (12), followed by Harvard University (11) and Hong Kong Polytech University (10). The sum of times cited of La Trobe University ranked first of all the institutions (791), follow by Hong Kong Polytech University (719) and University Munich (663). Fig.3B is the co-authorship relationship analysis of institutions. It shows that Harvard University and Natl Taiwan University had closely collaborated with their affiliated hospitals and research centers. In general, cooperation between the institutions were relatively weak. (Fig.3B)

\subsection{The Distribution and Co-authorship Analysis of Authors}

The top 8 most productive authors in PF field are shown in Fig.4A. Rompe JD published the largest number of articles (23), follow by Landorf KB (22), Maffulli N (14), Menz HB (14) and Schmitz C (13). The cited time of Rompe JD ranked first (1115), followed by Landorf KB (764) and Maffulli N (600). The Hindex of Rompe JD (18) ranked first of all the authors, follow byLandorf KB (14) and Schmitz C (10). Fig.4B shows the co-authorship relationship analysis of authors. Only authors cited a minimum of 20 times were included. 95 authors met the threshold and were selected for analyzing. It shows that authors in the same country have relatively close collaboration. Nevertheless, cooperation between authors from different country is weak.

\subsection{The Distribution and Co-authorship Analysis of Published Journals}


All publications were published in 367 journals. Only 32 (8.72\%) journals published more than 10 papers. The top 10 journals that published the most papers are showed in Fig.5A. The journal with the greatest number of publications was Foot \& Ankle International, with a total of 122 (8.54\%) papers. At the second position was Journal of the American Podiatric Medical Association with 61 (4.27\%) paper, followed by Journal of Foot \& Ankle Surgery with 59 (4.13\%), American Family Physician with 29 (3.15\%) and Journal of Orthopaedic \& Sports Physical Therapy with 28(1.96\%). These top 5 journals account for $20.9 \%$ of all the papers. The H-index of Foot \& Ankle International ranked first (36), followed by Journal of the American Podiatric Medical Association (19), American Journal of Sports Medicine(16), Journal of Orthopaedic \& Sports Physical therapy (14) and Journal of Bone and Joint Surgery-American Volume (13). The cited time of Foot \& Ankle International (3771), followed by Journal of Bone and Joint SurgeryAmerican Volume (1524) and British Journal of Sports Medicine (1327). Fig.5B plots the co-authorship relationship of journals. Only journals cited a minimum of 100 times were included. 67 journals met the threshold and selected for analyzing. Foot \& Ankle International, Journal of Bone and Joint SurgeryAmerican Volume and American Journal of Sports Medicine were at the center of research. In general, cooperation between journals is relatively weak.

Table 1 shows the top 10 cited articles in terms of title, journal, authors, years and citation numbers. The highest and the lowest number of citations for an article was 844 and 200. Two of these top ten cited articles were published in Foot \& Ankle International. All the 10 papers were in English. 8 papers were coauthored.

\subsection{The Keywords Analysis of Research Hotspots on Study}

Keywords co-occurrence can effectively reflect the research hotspots and provide support for the research. Keywords and research focuses related to PF was visualized by VOS viewer and shown in Fig.6. The bigger nodes and darker color show a larger weight of the keyword. There were 6 clusters with highfrequency in the field of PF. The cluster name was refined according to the keywords contained in each cluster. The six cluster are mainly about diagnose, treatment, injury site, cause of disease, related diseases and examine.

Table 2 shows the 25 meaningful keywords with the strongest citation burst, which represented the research frontiers. The red and blue bars represented the frequently- and infrequently-cited keywords, respectively. Fig.7 shows the keywords timeline view of publications. The results indicated that growth factor, wave therapy, corticosteroid, foot function index and physical therapy are the research hotspots in the recent years.

\section{Discussion}

\subsection{Trends of publications related to PF}

Bibliometric analysis is a mature tool to quantify the characteristics and scholarly impact, and it has been applied vastly to assess the merits of a specific field. ${ }^{14,15} \mathrm{PF}$ research has made great progress in 
recent years. In this article, we identified and summarized the papers related to PF, and compared the papers from different countries, institutes and journals, and showed the global trends of researches by visual tools. The result will be helpful in guiding researchers in selecting relevant topics, finding suitable teams to collaborate with and research platforms to use for their research.

There is a stable rising trend both in the number of published papers and relative research interest in the past 20 years. It suggests that the development of PF research has a rapid stage of progress and attracted more attention in the global medical field. More achievements had also been made. The study found that $66.5 \%$ of total articles were published by the top five productive countries (the United States, China, Germany, UK and Australia), and the top productive institutions were all from these countries. It indicated that worldwide research results of PF were concentrated in America, West Europe, East Asia and Australia.

USA made the most academic contributions to this area having the highest total publications (493, $34.50 \%$ ) and H-index (65), suggesting that USA dominates studies of PF. The most possible reasons for USA's great contributions may be related to technological, economic and academic advantages. In addition, substantial research funds are invested in medical research to increase the quality of researches. Nevertheless, the qualities of researches of China is relatively low, need to improve its qualities of publications concerning PF. China has an advantage in recruitment of participants because of the large population and high prevalence of lumbar degenerative disorders, but China is still a developing country with relatively backward technological strength. Furthermore, the amount of government funds is much lower than USA. For example, Chinese government funds in medical research only account for $2-3 \%$ of the total governments funds. For all this, China's research influence is still more significant than the other counties and cannot be ignored.

La Trobe University is the most productive organizations in the field of PF. La Trobe University and University Munich ranked first side by side in $\mathrm{H}$-index. La Trobe University ranked first in total citation numbers. It suggesting that the significant studies related to PF are more likely to be published by these institutions, and researchers who are interested in PF may cooperate with these institutions. Regarding the productive journals, Foot \& Ankle Internationa/ ranked first in total publications, H-index and cited time. This was a reflection of the great influence of Foot \& Ankle International and its leading position in the field of PF. There is no doubt that authors interested in PF should pay more attention to La Trobe University and Foot \& Ankle International.

Co-authorship research is an important content of bibliometrics and the level of research collaboration is an index to assess the current research status. The network map revealed that the centrality and density value of this study was not high. The interaction between countries, institutions, journals and authors were relatively weak. Therefore, it is urgent to strengthen the international academic cooperation between countries/regions and institutions. Furthermore, forming an academic community is beneficial to the development of research in the future.

\subsection{Studies focused on PF}


Under normal circumstances, doctors can differentiate causes of plantar fasciitis during the patient history and physical examination. To diagnose objectively, MRI is the only imaging method that can precisely visualize lesions of the plantar fasciitis, whether they be musculoaponeurositides, enthesopathies or tears, and whether they be acute or chronic, with or without complications at present. By its direct visualization of the lesion, MRI enables an accurate assessment of the injury to be made and thereby better orients the therapeutic strategy. Currently, the clinical efficacy of treatment for PF is controversial. The relationship between individual patient's characteristics and its potential predictive value on outcomes has not been studied. In addition, there is no scoring system to determine the severity of PF and no prognostic model in choosing between conservative or surgical treatment. ${ }^{16-18}$

In past decades, most physicians only paid attention to patients' improvement of symptoms and signs. But with the transformation of medical model to "bio-psycho-social medical model", physicians should consider the whole body, including patients' psychological, spiritual and social adaptability, that is, to emphasize the improvement of patients' quality of life. Through the assessment of quality of life, physicians will have more understanding of the patients' physical, psychological and social functions, carry out effective psychological guidance, so that they can truly achieve the purpose of treating diseases, reducing trauma, recovering functions and improving the quality of life. ${ }^{19,20}$

\subsection{Strengths and limitations}

To the best of our knowledge, the current study is the first to analyze the quality and quantity of researches using bibliometric analysis and visualization tool in the field of PF. To guarantee the objectivity and comprehensiveness, we conducted a systematic literature search in the WOS, which could offer powerful data from various aspects with a high and powerful recognition. Although these notable strengths, this study also has some limitations. First, bibliometric analyses only contain the published literature in WOS database, the unpublished and non-English articles were not included. Second, bibliometric data are changing over time, the delay of the indexation may account for the slight difference in the results retrieved. Third, all citations were treated in the same way whether it was cited for its positive contribution or for its negative impact or poor quality. Also the authors might tend to cite papers from the journals in which they hoped to publish their research.

\section{Conclusions}

This study provided a basic worldwide overview of research publications and relative research interest on PF. The number of publications showed an upward trend with a stable rise in recent years. USA is the country with the highest productivity, not only in quality, but also in quantity. La Trobe University has been the largest contributor in this field. Foot \& Ankle International is the best journal related to PF. Growth factor, wave therapy, corticosteroid, foot function index and physical therapy are the research hotspots in the recent years. Indeed, this study provides great insights to the growth and development of PF. Moreover, it will contribute to the growth of the international frontier of PF. 


\section{Abbreviations}

PF: plantar fasciitis

WOS: Web of Science

\section{Declarations}

\section{Ethics approval and consent to participate}

Not applicable.

\section{Consent for publication}

Participants signed informed consents prior to the study.

\section{Availability of data and materials}

Not applicable.

\section{Conflicting Interests}

The author(s) declared no potential conflicts of interest with respect to the research, authorship, and/or publication of this article.

\section{Funding}

The author(s) received no financial support for the research, authorship, and/or publication of this article.

\section{Authors' contributions}

XYX and YJS designed the study. JZL and MCY collected the data. CQX, QSM and XD did the date analysis. $\mathrm{XYX}$ and $\mathrm{MCY}$ wrote the manuscript. JMM and MCY revised the manuscript, and decided to submit the manuscript for publication.

XYX, YJS and JLZ contributed equally to this work and should be considered as equal first authors. MCY and JMM should both be corresponding authors. All authors read and approved the final manuscript.

\section{Acknowledgements}

Not applicable

\section{References}

1. Thomas JL, Christensen JC, Kravitz SR, et al. The diagnosis and treatment of heel pain: a clinical practice guideline-revision 2010. J Foot Ankle Surg, 2010, 49:S1-S19.】 
2. Tu P, Bytomski JR. Diagnosis of heel pain. Am Fam Physician, 2011, 84:909-916.

3. Lemont H, Ammirati KM, Usen N. Plantar fasciitis: a degenerative process (fasciosis) without inflammation. J Am Podiatr Med Assoc, 2003, 93:234-237.

4. Wearing SC, Smeathers JE, Urry SR, et al. The pathomechanics of plantar fasciitis. Sports Med, 2006, 36:585-611.

5. Cole C, Seto C, Gazewood J. Plantar fasciitis: evidence-based review of diagnosis and therapy. Am Fam Physician, 2005, 72:2237-2242.凶

6. Maier M, Steinborn M, Schmitz C, et al. Extracorporeal shock wave application for chronic plantar fasciitis associated with heel spurs: prediction of outcome by magnetic resonance imaging. J Rheumatol, 2000, 27:2455-2462.8

7. Ergul S, Ardahan M, Temel AB, Yildirim BO. Bibliometric review of references of nursing research papers during the decade 1994-2003 in Turkey. Int Nurs Rev. 2010; 57:49-55. doi:10.1111/ j.14667657.2009.00770.x $\otimes$

8. Zhang TS, Qin HL, Wang T, et al. Global publication trends and research hotspots of nonalcoholic fatty liver disease: a biblio- metric analysis and systematic review. Springerplus. 2015;4: 776. doi:10.1186/s40064-015-1542-1 》

9. Sun J, Wang MH, Ho YS. A historical review and bibliometric analysis of research on estuary pollution. Mar Pollut Bull. 2012; 64:13-21. doi: 10.1016/j.marpolbul.2011.10.034 \

10. Boyce R, Rosch R, Finlayson A, et al. Use of a bibliometric liter- ature review to assess medical research capacity in post-conflict and developing countries: Somaliland 1991-2013. Trop Med Int Health. 2015; 20:1507-1515. doi:10.1111/tmi.12590凶

11. Chen C, Hu Z, Liu S, et al. Emerging trends in regenerative medicine: a scientometric analysis in CiteSpace. Expert Opin Biol Ther 2012; 12:593-608.ष

12. Fajardo-Ortiz D, Duran L, Moreno L, et al. Mapping knowledge translation and innovation processes in Cancer Drug Development: the case of liposomal doxorubicin.J Transl Med 2014;12:227.

13. van Eck NJ, Waltman L. Software survey: VOSviewer, a computer program for bibliometric mapping. Scientometrics 2010; 84:523-38.囚

14. Allen L, Jones $C$, Dolby $K$, et al. Looking for landmarks: the role of expert review and bibliometric analysis in evaluating scientific publication outputs. PLoS One 2009;4:e5910.

15. Liu YH, Wang SQ, Xue JH, et al. Hundred top-cited articles focusing on acute kidney injury: a bibliometric analysis. BMJ Open 2016;6:e011630.8

16. Tu P, Bytomski J R. Diagnosis of heel pain[J]. American Family Physician, 2011, 84(8):909-916.

17. Roger B, Grenier P. MRI of plantar fasciitis[J]. European Radiology, 1997, 7(9):1430-1435.

18. Meng-chen Yin, Yin-jie Yan, et al. Development and Validation of a Novel Scoring System for Severity of Plantar Fasciitis[J]. Orthopaedic Surgery, 2020.

19. Jacobs WC, Rubinstein SM, Willems PC, et al. The evidence on surgical interventions for low back disorders, an overview of systematic reviews. Eur Spine J 2013; 22:1936-49. 
20. Forsth P, Michaelsson K, Sanden B. Does fusion improve the outcome after involving 5390 patients. Bone Joint J 2013;95-B:960-5.

\section{Tables}

Tables 1-2 are available in the Supplementary Files

\section{Figures}

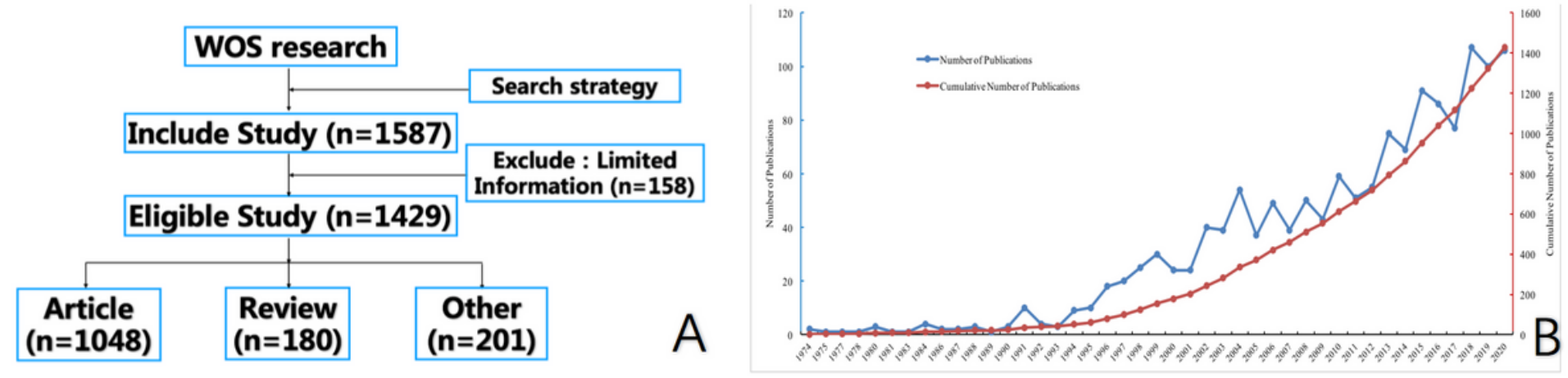

Figure 1

(A) Flow chart; (B) The annual trends of publications 

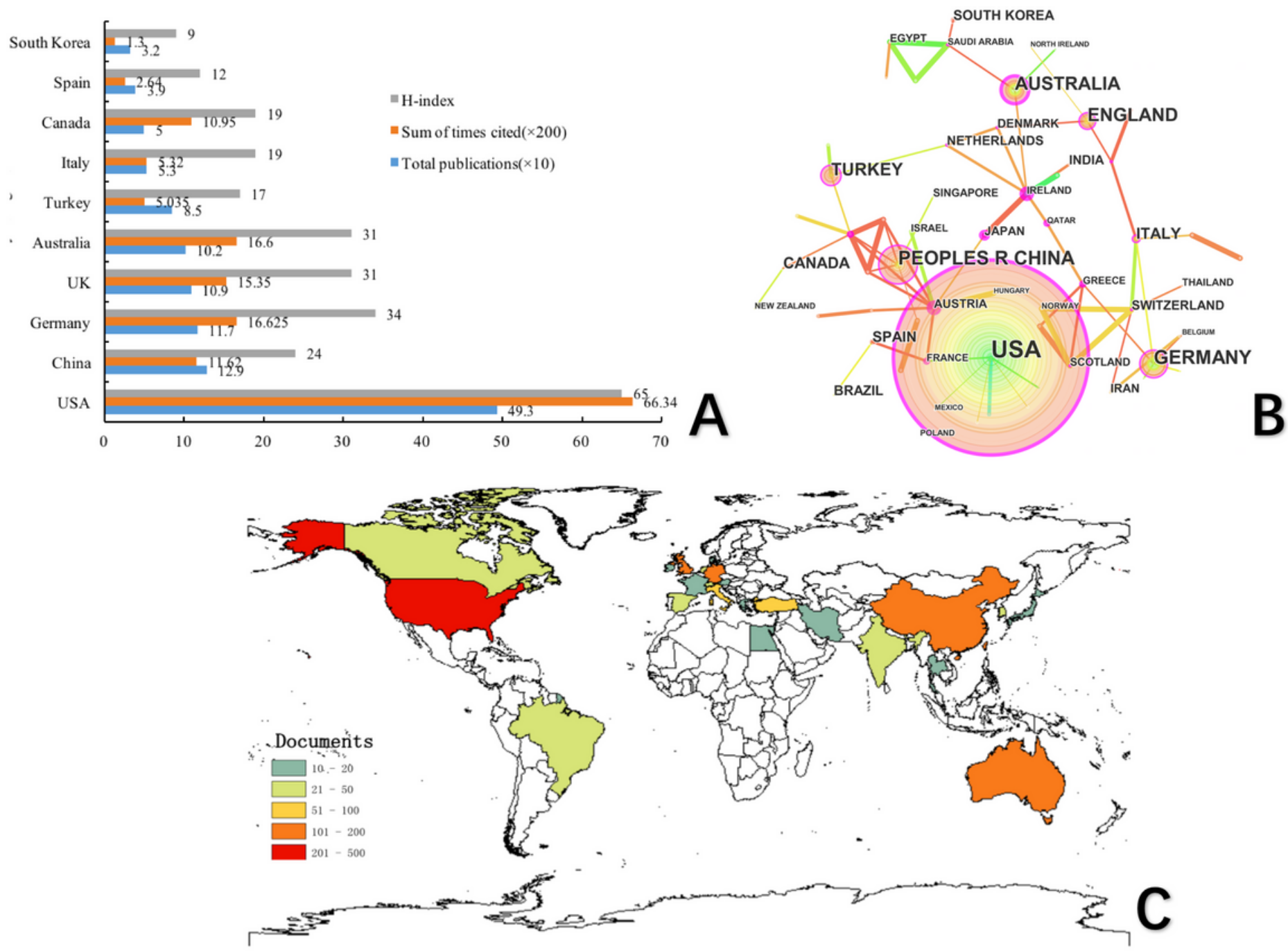

\section{Figure 2}

(A) The publication number, $\mathrm{H}$-index and cited times of the top 10 countries; (B) The country coauthorship network of publications; (C) Map of worldwide research productivity. Note: The designations employed and the presentation of the material on this map do not imply the expression of any opinion whatsoever on the part of Research Square concerning the legal status of any country, territory, city or area or of its authorities, or concerning the delimitation of its frontiers or boundaries. This map has been provided by the authors. 

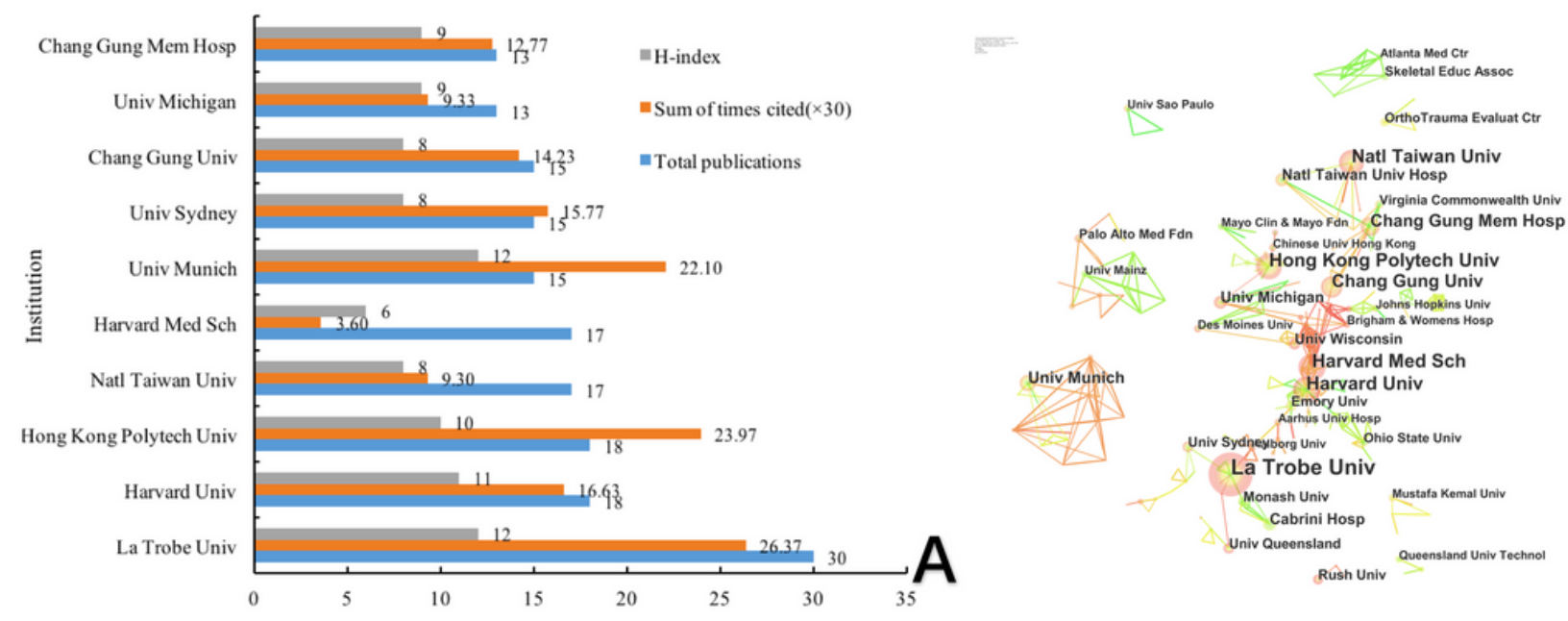

B

\section{Figure 3}

(A) The publication number, $\mathrm{H}$-index and cited times of the top 10 institutions; (B) The institutions coauthorship network of publications
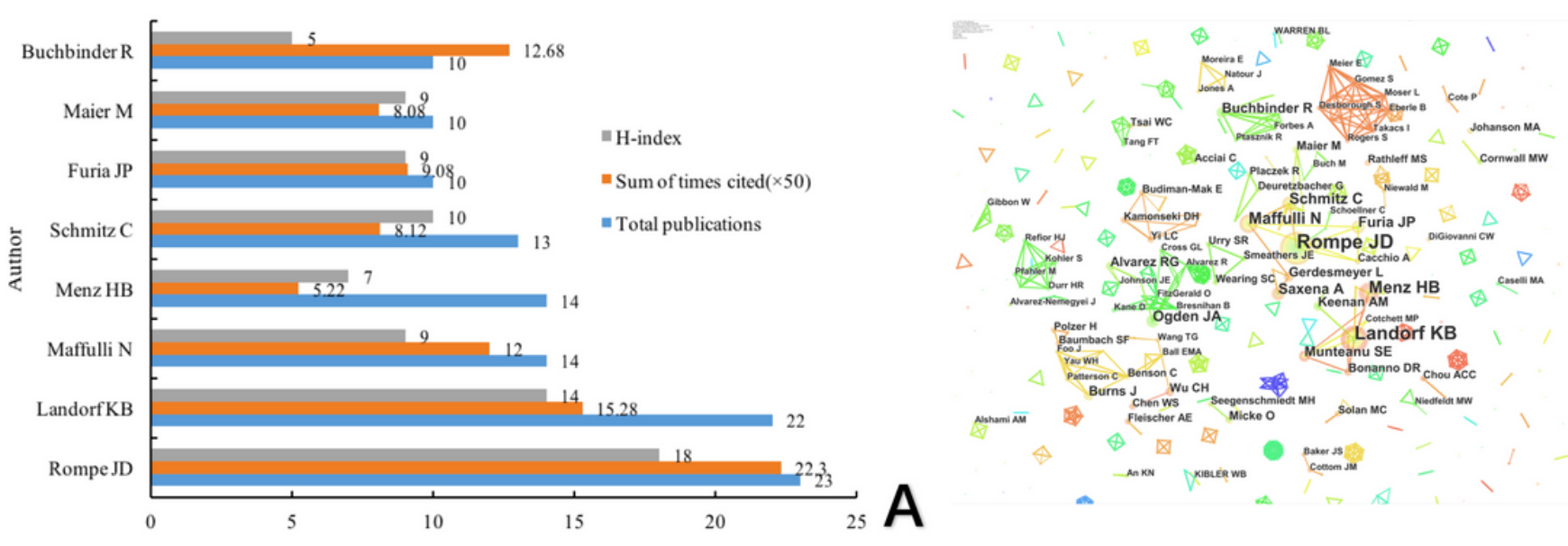

B

\section{Figure 4}

(A) The publication number, $\mathrm{H}$-index and cited times of the top 8 authors;(B) The authors co-authorship

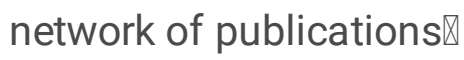




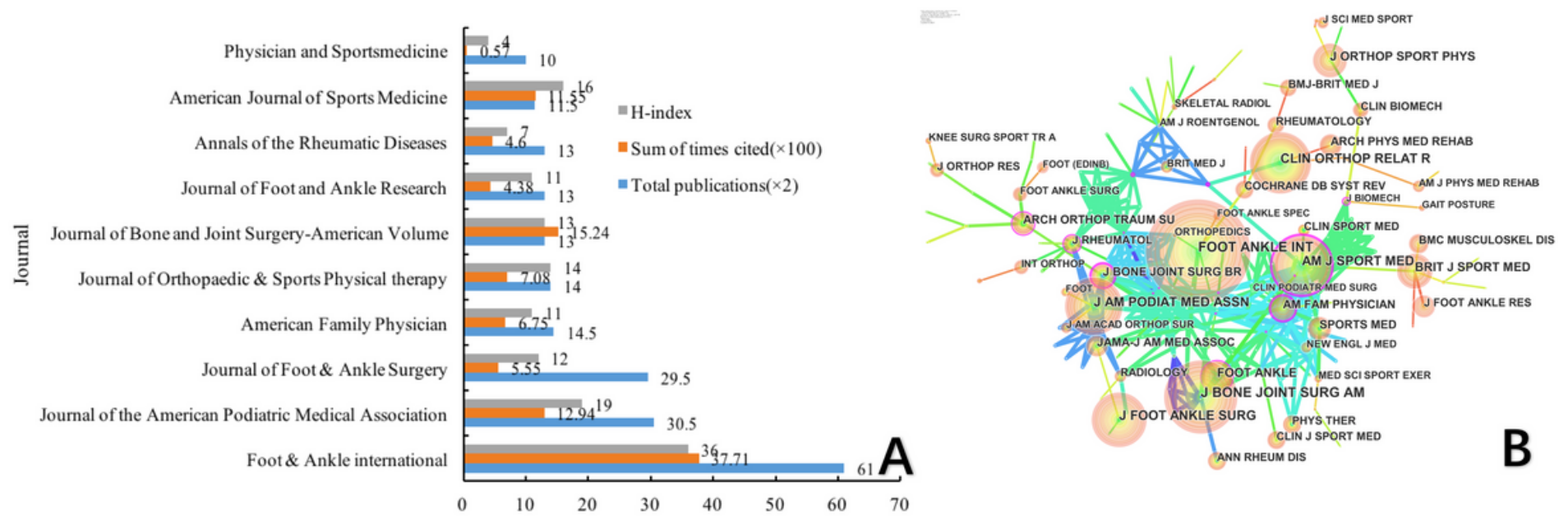

Figure 5

(A) The publication number, H-index and cited times of the top 10 journals; (B) The journals co-authorship network of publications $\rrbracket$
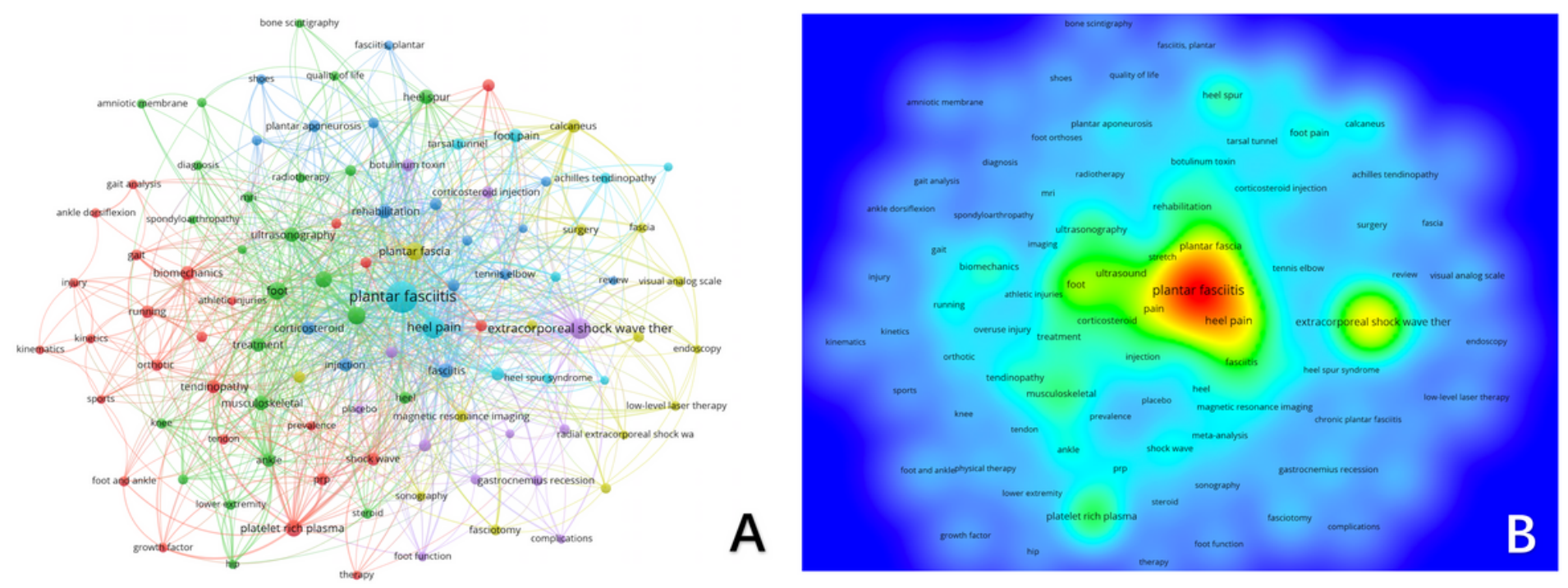

Figure 6

(A) Keywords co-occurrence network of publications; (B) Keywords density visualization map of publications 


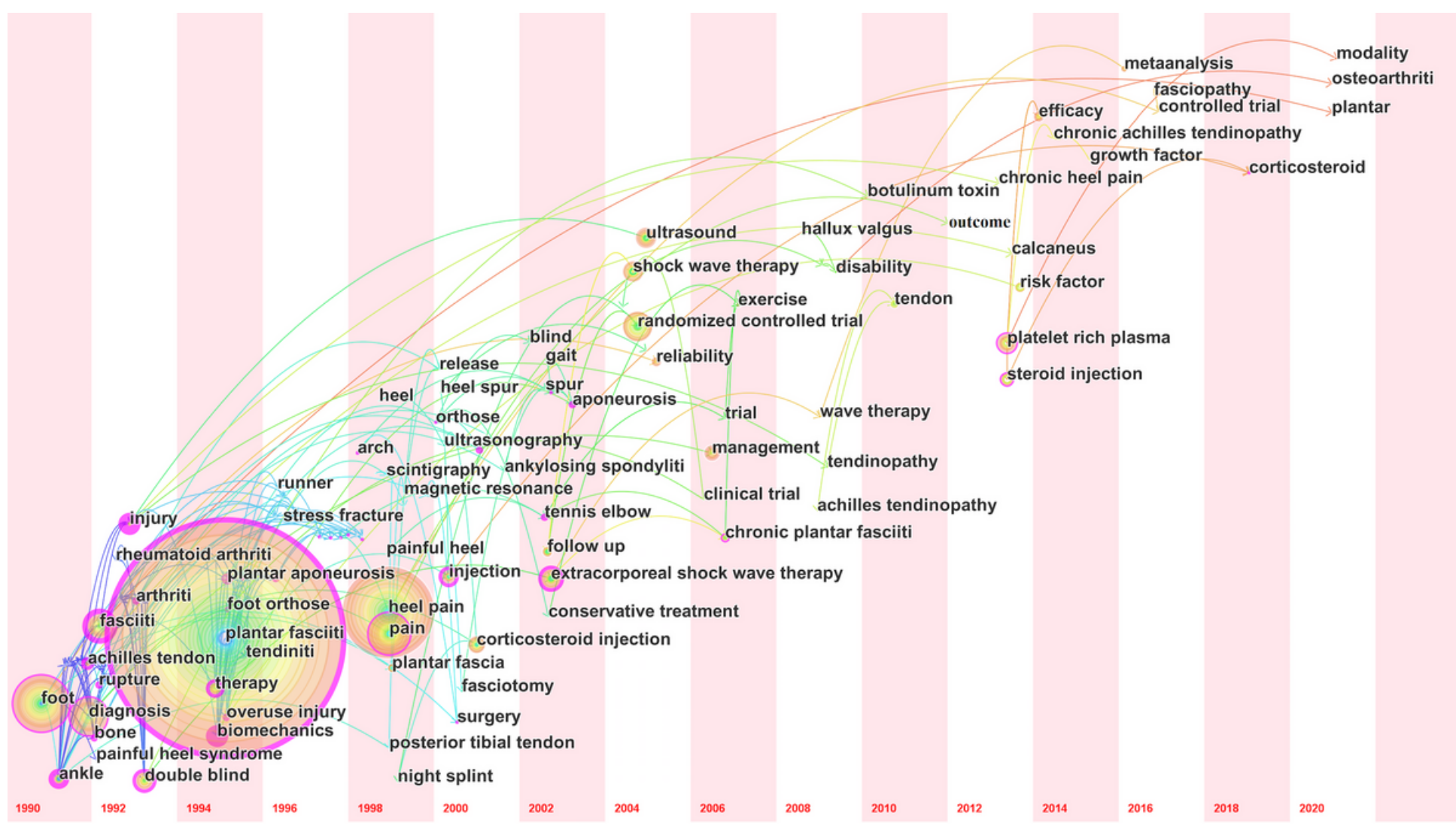

Figure 7

The keywords timeline view of publications

\section{Supplementary Files}

This is a list of supplementary files associated with this preprint. Click to download.

- Table.docx 